\title{
Concurrent HPV-related oropharyngeal carcinoma in four couples
}

Hans Prakash Sathasivam a , Ramya Bhatia b, Paula Bradley c, Andrew Robson d, Vinidh Paleri e , Helen Cocks ${ }^{\dagger}$, Nashreen Oozeer ${ }^{\dagger}$, Debra Milne ${ }^{g}$, Philip Sloan ${ }^{a}$, Max Robinson ${ }^{a}$

a Centre for Oral Health Research, Newcastle University, Newcastle upon Tyne, UK. b HPV Research Group, Division of Pathology, The University of Edinburgh, The Queen's Medical Research Institute, Edinburgh, UK.

c Northumbria General Practice Training Programme, Health Education North East, Newcastle Upon Tyne, UK.

d Department of Otolaryngology, North Cumbria University Hospitals, Carlisle, UK.

e Head and Neck Unit, The Royal Marsden NHS Foundation Trust and Institute of Cancer Research, London, UK.

${ }^{f}$ Department of Otolaryngology, City Hospitals Sunderland, Sunderland, UK.

g South of Tyne and Wear Clinical Pathology Services, Queen Elizabeth Hospital, Gateshead, UK.

\section{Corresponding author}

Dr Max Robinson

Centre for Oral Health Research

Newcastle University

Framlington Place

Newcastle-upon-Tyne

NE2 4BW

United Kingdom

Tel: +44191222 8391.

Email: max.robinson@newcastle.ac.uk

\section{Word count:}

Abstract: 248 words Manuscript: 1932 words

Number of tables: 2

Number of figures: 0

Number of references: 27 


\section{Concurrent HPV-related oropharyngeal carcinoma in four couples}

\section{Abstract \\ Objectives}

Typically, HPV-related cancers are sexually transmitted, however, the natural history of HPV-related oropharyngeal squamous cell carcinoma (OPSCC) is unclear. HPV16 transmission has been reported previously between five couples with OPSCC. We report the clinico-pathological features of a further four couples with HPV-related OPSCC and compare them with the published cases.

Patients and Methods

We identified four couples in long-term heterosexual relationships that all had HPVrelated OPSCC. The couples were treated at three UK hospitals and presented between 2009-2015. HPV tests included p16 immunohistochemistry, high-risk HPV DNA in-situ hybridization and Roche Cobas HPV test. DNA sequencing was used to determine the HPV variant.

Results

The four couples represented $<2 \%$ of patients with HPV-related OPSCC at the three contributing hospitals (8 of 457 consecutive patients). The couples' tumours all contained HPV16. The mean age was 63 years old (range 52-72 years). The interval between the index cancer and the partner's cancer was 16, 24, 26 and 64 months respectively. The majority of patients had Stage I disease (UICC TNM8). Six of eight patients are disease free, one patient is alive with disease and there was one death from loco-regional recurrence.

\section{Conclusion}

This report highlights the occurrence of HPV-related OPSCC in heterosexual couples and raises the possibility of transmission of HPV16. Despite increasing prevalence of 
HPV-related OPSCC and increased awareness of the disease, there is a paucity of couples with the disease, suggesting either under-reporting or that the development of OPSCC following HPV transmission between couples is a rare event.

\section{Keywords}

Oropharynx; squamous cell carcinoma; human papillomavirus; HPV-16; couples

\section{Introduction}

It is well known that human papillomavirus (HPV) causes cervical squamous cell carcinoma. The natural history of the disease has been well characterized over the last 30 years and this knowledge underpins screening programs and vaccination strategies for women [1]. More recently, an increase in oropharyngeal squamous cell carcinoma (OPSCC) in the USA and Europe has been attributed to oncogenic HPV infection [2-4], however, the natural history of the disease is unclear [5].

There are epidemiological studies showing an association of HPV-related OPSCC with sexual behaviour [6-8]. A recent systematic review has also suggested that there is a small increased risk for HPV-related cancers amongst spouses/partners of patients with HPV-driven cancers [9]. Furthermore, population studies in Sweden indicated that women with cervical cancer and their husbands both have a higher standard incidence ratio of tonsillar cancer and upper aerodigestive cancers $[10,11]$. These studies provide circumstantial evidence that HPV transmission between individuals can result in OPSCC, however, there is no evidence of direct transmission and causation per se. 
Only five couples with HPV-related OPSCC have been reported to date [12-15]. For each set of couples, DNA sequencing of the tumours revealed distinct HPV16 variants shared by partners, increasing the likelihood that the virus was acquired by direct transmission and was causative.

Interestingly, D'Souza et al (2014) reported that oncogenic HPV could be detected in the oral cavities of around $60 \%$ of patients with HPV-related OPSCC, but their partners had a very low prevalence of oncogenic HPV DNA; around 1.1\% [16]. These data suggest partners of patients with HPV-related OPSCC have a very low risk of oral HPV transmission and consequently a small or negligible risk of developing HPVrelated OPSCC [17]. Here we report the clinico-pathological features of four couples with HPV-related OPSCC and compare them with the previously published cases. We use the cases to frame a discussion around infectivity, transmission and the natural history of HPV-related OPSCC.

\section{Methods}

We identified patients with HPV-related OPSCC that were in long-term heterosexual relationships with a partner that also had HPV-related OPSCC from a prospective database of patients with HPV-related OPSCC from three UK hospitals (Cancer centers at City Hospitals Sunderland, Newcastle upon Tyne Hospitals and North Cumbria University Hospital) compiled from January 2009 until December 2017 (9 years). Written consent was obtained from the patients to use their anonymized clinical data for publication. Following patient consent, the clinical features were determined by review of the medical notes and the HPV tests were re-examined. p16 was detected by immunohistochemistry (CINtec Histology, Roche mtm laboratories AG, Germany) 
and high-risk HPV DNA was detected by in-situ hybridisation (Inform HPV III Family 16 Probe B, Ventana Medical Systems Inc, USA), using a Benchmark Ultra autostainer (Roche Molecular Systems Inc. USA), according to the manufacturer's instructions.

Genomic DNA was extracted from formalin-fixed paraffin-embedded tissue scrolls using the Cobas DNA extraction kit (Roche Molecular Systems Inc. USA). Standard operating procedures were followed to prevent contamination of samples during preparation for downstream analysis. In addition, control samples (known positive and negative OPSCC) were prepared alongside test samples to quality assure the results. 400ng of genomic DNA was analysed using the Cobas HPV test on a Cobas 4800 unit (Roche Molecular Systems Inc. USA), according to the manufacturer's instructions. The Cobas HPV test is clinically validated and FDA approved for use in cervical screening.

The sequence of HPV was determined by PCR amplification using two sets of primers that amplify regions nucleotides 75 to 206 and 274 to 338 within E6 gene as previously published $[18,19]$. Sequencing was performed on purified PCR product (Source Bioscience, UK) and sequences were analysed using the reference HPV-16 sequence (K02718) [20]

\section{Results}

The four couples represented $<2 \%$ of patients with HPV-related OPSCC at the three contributing hospitals (8 of 457 consecutive patients, 1.75\%). The clinico-pathological features of the four couples (8 patients) are summarised in Table 1. Briefly, the mean age of the individuals at diagnosis was 63 years old (range $52-72$ years). The 
relationships were long-standing (mean duration 36 years; range 24-50 years). The index tumour was equally likely to be the male or female in the relationship ( 2 males, 2 females). The interval between presentation of the index cancer and the partner cancer was $16,24,26$, and 64 months respectively. The majority of patients were never smokers ( 6 of 8 patients) and where alcohol consumption was known, there were equal numbers between those who consumed alcohol and those that did not. None of the patients had undergone a tonsillectomy prior to the diagnosis of oropharyngeal cancer. None of the female patients had a history of uterine cervix dysplasia or cancer. The majority of patient had Stage I disease (UICC TNM8) and all patients were treated with curative intent. Treatment was variable and included surgery alone, surgery with adjuvant radiotherapy and chemoradiotherapy, however, the majority received chemoradiotherapy (6 of 8 patients). Six of eight patients are disease free, one patient is alive with disease and there was one death from locoregional recurrence.

All tumours were $\mathrm{p} 16$ positive by immunohistochemistry using the validated clinical cut off of strong and diffuse nuclear and cytoplasmic expression in $>70 \%$ of the malignant cells $[21,22]$. The majority of cases ( 7 of 8 patients) showed evidence of high risk HPV DNA by in situ hybridization; one case was negative. The HPV Cobas tests demonstrated that all the samples contained amplifiable HPV16 DNA (Table 1).

HPV sequencing results demonstrated that all the couples harboured the European A1 lineage of HPV16. Couple 1 harboured a mutation at nucleotide position 350 changing the nucleotide $T$ to $G$ (indicated as T350G mutation). Interestingly, in Couple 
4, only the female partner had the T350G mutations whereas the corresponding male partner had the European A1 variant of HPV-16.

The clinico-pathological features of the previously published cases are presented in Table 2. Analysing all the cases ( 9 couples/18 patients), the mean age of the individuals at diagnosis was 62 years old (range 52-75 years old). The relationships were long-standing (mean duration 29 years; range 10-50 years). The index tumour was equally likely to be the male or female in the relationship ( 4 males, 4 females, 1 synchronous). Where smoking status was known, most were never smokers (10 of 16 patients) and only one was a smoker at diagnosis. Where alcohol consumption was known, the majority did not consume alcohol (8 of 14 patients). The majority of patients (13 of 18) presented with Stage I disease (UICC/AJCC TNM8). All cancers harboured HPV16. Treatment was variable and included surgery alone, surgery with adjuvant radiotherapy and chemoradiotherapy, however, the majority received some form of chemoradiotherapy (11 of 18 patients). The patients generally had a favorable outcome and for those with follow up data, 13 of 14 were survivors; one died of locoregional recurrence.

\section{Discussion}

These 18 cases of HPV-related OPSCC in nine longstanding heterosexual relationships have features that indicate a high likelihood of transmission of the aetiological agent to the partner. All 18 cases harbored HPV-16, which accounts for around $90 \%$ of HPV-related OPSCC [23]. 
Gene sequencing of HPV DNA from the four couples previously reported [13-15] revealed that each individual couple had highly phylogenetically similar HPV16 strains between the partners, making transmission highly likely in these instances although the possibility of a similar source of infection cannot be completely ruled out [13-15]. Some sequence variations were reported in all three reports but all had the nucleotide T at positions 350. In the four couples from our series however, we found that Couple 1 and the female of Couple 4 had the $\mathrm{G}$ nucleotide in this position. This nucleotide change causes an amino acid change of Leucine to Valine at position 83 (L83V). There is evidence to suggest that $350 \mathrm{G}$ variant is significantly associated with high grade cervical lesions and invasive cervical cancer [24]. However, an HPV variant study conducted in 2013 found that it was dependent on geographical location [25]. While 350G E6 was associated with an increased risk of developing cervical cancer in Central and South America, this was not the case in Europe or Central Asia. There is limited data on T350G mutation in OPSCC. None of the previous case studies indicated the presence of this mutation.

It is well known that HPV is a ubiquitous infective agent and around $80 \%$ of sexually active adults have acquired genital infection at some point during their lifetime, however, the majority of infections are cleared [26]. Oral HPV infection has a bimodal age distribution, with peak prevalence among individuals aged 55-64 years old [27] and the majority of the individuals in this study fitted this demographic. Partners in longstanding relationships have already likely shared their infections, which in these partners would have been shared for at least a decade and for one couple almost five decades, perhaps long enough to facilitate HPV-driven carcinogenesis [17]. Furthermore, couples tend to share other environmental risk factors for the 
development of cancer, such as smoking in lung cancer and ultra-violet (UV) radiation in skin cancer [10]. However, smoking did not appear to influence the development of the cancers documented here, as the majority were never smokers or current nonsmokers. Perhaps factors such as advanced age, co-morbidities and diet, with their known effects on immune competence, may have reduced the ability to combat the virus with inexorable progression to cancer; however, this is speculative.

Only $1.75 \%$ of patients with HPV-related OPSCC were couples in this cohort. Despite the obvious lack of infectivity from HPV-related OPSCC as described by D'Souza et al (2014) [16], it is possible that the HPV-16 variants in these couples have subtly different virulence factors, which makes persistent infection more likely, rendering the virus more oncogenic [14]. It is conceivable that virulence factors are encoded by acquired virus mutations or epigenetic changes, however, further understanding of the natural history of the disease in the oropharynx is required to determine if such factors play a role in the pathogenesis of the disease.

It is inevitable that the occurrence of the disease in these individuals is likely to be multifactorial and the cases may represent a rare constellation of factors permissive for transmission, persistent infection and transformation to cancer. In other words, they may be rare occurrences that are simply stochastic events (i.e. subject to the variation of chance), although the odds are surely very low. It will be interesting to see if more couples with HPV-related OPSCC emerge as the number of incident cases of the disease accumulate. To date, these individuals provide evidence that the disease is communicable in rare circumstances, however, there is insufficient evidence to 
change the advice recommended by Fakhry and D'Souza (2013) to partners of people with HPV related OPSCC:

- 'The risk of HPV-related OPSCC may be slightly higher among spouses of HPV-related OPSCC, but this cancer remains rare among spouses'.

- 'There are no recommended screening tests for HPV-related OPSCC'.

- 'You have already likely shared whatever infections you have'.

- 'You do not need to change your sexual behavior'.

- 'Female partners should have regular cervical Pap screening'.[17]

Regarding the last point, the nine females described to date were all over 50 yearsold at diagnosis and would typically be invited for cervical screening every 5 years; in fact, three of the patients were in their eighth decade and would not be eligible for screening. Consequently, there is uncertainty regarding cervical screening advice for women who have HPV-related OPSCC or whose partners have the disease.

It is important to note that the instances of couples with HPV-related oropharyngeal cancer reported to date lack detailed sexual histories and may underestimate the burden of HPV-related disease and exposure to infection over time. Future studies should attempt to address these issues and also provide accurate epidemiological data. Such information will provide a better understanding of the risks of HPV transmission and can be used to counsel individuals with HPV-related SCC and their partners.

\section{Acknowledgements}

The authors would like to thank the patients for agreeing to participate in this study. Lesley Old prepared genomic DNA from the tissue samples (Newcastle University). 
Anna Long and Tracy Knox (Cellular Pathology, Newcastle upon Tyne Hospitals NHS Foundation Trust) carried out the HPV diagnostic tests. Oliver Ruiz Butterworth (Newcastle University) translated the Japanese manuscript [12]. 


\section{References}

[1] zur Hausen H. Papillomaviruses in the causation of human cancers - a brief historical account. Virology 2009;384:260-5.

[2] Marur S, D'Souza G, Westra WH, Forastiere AA. HPV-associated head and neck cancer: A virus-related cancer epidemic. Lancet Oncol 2010;11:781-9.

[3] Chaturvedi AK, Engels EA, Pfeiffer RM, Hernandez BY, Xiao W, Kim E, et al. Human papillomavirus and rising oropharyngeal cancer incidence in the United States. J Clin Oncol 2011;29:4294-301.

[4] Schache AG, Powell NG, Cuschieri KS, Robinson M, Leary S, Mehanna H, et al. HPV-Related Oropharynx Cancer in the United Kingdom: An Evolution in the Understanding of Disease Etiology. Cancer Res 2016;76:6598-606.

[5] D'Souza G, Dempsey A. The role of HPV in head and neck cancer and review of the HPV vaccine. Prev Med (Baltim) 2011;53:S5-11.

[6] Heck JE, Berthiller J, Vaccarella S, Winn DM, Smith EM, Shan'gina O, et al. Sexual behaviours and the risk of head and neck cancers: A pooled analysis in the International Head and Neck Cancer Epidemiology (INHANCE) consortium. Int J Epidemiol 2010;39:166-81.

[7] Gillison ML, D'Souza G, Westra W, Sugar E, Xiao W, Begum S, et al. Distinct risk factor profiles for human papillomavirus type 16-positive and human papillomavirus type 16-negative head and neck cancers. J Natl Cancer Inst 2008;100:407-20.

[8] D'Souza G, Kreimer AR, Viscidi R, Pawlita M, Fakhry C, KOch WM, et al. Case-Control Study of Human Papillomavirus and Oropharyngeal Cancer. N Engl J Med 2007;356:1944-56.

[9] Mirghani H, Sturgis EM, Aupérin A, Monsonego J, Blanchard P. Is there an increased risk of cancer among spouses of patients with an HPV-related cancer: A systematic review. Oral Oncol 2017;67:138-45.

[10] Weires M, Bermejo JL, Sundquist J, Hemminki K. Clustering of concordant and discordant cancer types in Swedish couples is rare. Eur J Cancer 2011;47:98106.

[11] Hemminki K, Dong C, Frisch M. Tonsillar and other upper aerodigestive tract cancers among cervical cancer patients and their husbands. Eur $\mathrm{J}$ Cancer Prev 2000;9:433-7.

[12] Uemaetomari I, Tobita T, Tabuchi K, Okubo H, Wada T, Hara A. A Case of Tonsillar Squamous Cell Carcinoma Arising in a Married Couple. Practica-OtoRhino-Laryngologica 2007;100:285-9.

[13] Haddad R, Crum C, Chen Z, Krane J, Posner M, Li Y, et al. HPV16 transmission between a couple with HPV-related head and neck cancer. Oral Oncol 2008;44:812-5.

[14] Andrews E, Shores C, Hayes DN, Couch M, Southerland J, Morris D, et al. 
Concurrent human papillomavirus-associated tonsillar carcinoma in 2 couples. $\mathrm{J}$ Infect Dis 2009;200:882-7.

[15] Brobst TD, García JJ, Price KA, Gao G, Smith DI, Price DL. Concurrent Human Papillomavirus-Positive Squamous Cell Carcinoma of the Oropharynx in a Married Couple. Case Rep Otolaryngol 2016;Article ID:8481235.

[16] D'Souza G, Gross ND, Pai SI, Haddad R, Anderson KS, Rajan S, et al. Oral Human Papillomavirus (HPV) infection in HPV-positive patients with oropharyngeal cancer and their partners. J Clin Oncol 2014;32:2408-15.

[17] Fakhry C, D'Souza G. Discussing the diagnosis of HPV-OSCC: Common questions and answers. Oral Oncol 2013;49:863-71.

[18] Larsson GL, Helenius G, Andersson S, Elgh F, Sorbe B, Karlsson MG. Human papillomavirus (HPV) and HPV 16-variant distribution in vulvar squamous cell carcinoma in Sweden. Int J Gynecol Cancer 2012;22:1413-9.

[19] Swan DC, Limor JR, Duncan KL, Rajeevan MS, Unger ER. Human papillomavirus type 16 variant assignment by pyrosequencing. J Virol Methods 2006;136:166-70.

[20] Burk RD, Harari A, Chen Z. Human papillomavirus genome variants. Virology 2013;445:232-43.

[21] Singhi AD, Westra WH. Comparison of human papillomavirus in situ hybridization and p16 immunohistochemistry in the detection of human papillomavirus-associated head and neck cancer based on a prospective clinical experience. Cancer 2010;116:2166-73.

[22] Jordan RC, Lingen MW, Perez-Ordonez B, He X, Pickard R, Koluder M, et al. Validation of Methods for Oropharyngeal Cancer HPV Status Determination in US Cooperative Group Trials. Am J Surg Pathol 2012;36:945-54.

[23] Kreimer AR, Clifford GM, Boyle P, Franceschi S. Human papillomavirus types in head and neck squamous cell carcinomas worldwide: a systematic review. Cancer Epidemiol Biomarkers Prev 2005;14:467-75.

[24] Zehbe I, Wilander E, Delius H, Tommasino M. Human papillomavirus 16 E6 variants are more prevalent in invasive cervical carcinoma than the prototype. Cancer Res 1998;58:829-33.

[25] Cornet I, Gheit T, lannacone MR, Vignat J, Sylla BS, Del Mistro A, et al. HPV16 genetic variation and the development of cervical cancer worldwide. $\mathrm{Br}$ J Cancer 2013;108:240-4.

[26] Woodman CB, Collins S, Winter H, Bailey A, Ellis J, Prior P, et al. Natural history of cervical human papillomavirus infection in young women: a longitudinal cohort study. Lancet $2001 ; 357: 1831-6$.

[27] Gillison ML, Broutian T, Pickard RKL, Tong Z, Xiao W, Kahle L, et al. Prevalence of Oral HPV Infection in the United States, 2009-2010. JAMA 2012;307:693-703. 

Table 1 HPV related squamous cell carcinoma in four couples.

\begin{tabular}{|c|c|c|c|c|}
\hline & \multicolumn{2}{|c|}{ Couple 1} & \multicolumn{2}{|c|}{ Couple 2} \\
\hline Sex & Male & Female & Male & Female \\
\hline Age at diagnosis & 53 & 52 & 71 & 72 \\
\hline Year of diagnosis & 2010 & 2012 & 2013 & 2011 \\
\hline $\begin{array}{l}\text { Duration of } \\
\text { relationship }\end{array}$ & \multicolumn{2}{|c|}{24 years } & \multicolumn{2}{|c|}{32 years } \\
\hline $\begin{array}{l}\text { Interval between } \\
\text { couple diagnosis }\end{array}$ & \multicolumn{2}{|c|}{24 months (male index tumour) } & \multicolumn{2}{|c|}{26 months (female index tumour) } \\
\hline Smoking status & $\begin{array}{l}\text { Former smoker } \\
\text { (22 years ago) }\end{array}$ & Never smoker & $\begin{array}{l}\text { Former smoker } \\
\text { (28 years ago) }\end{array}$ & Never smoker \\
\hline Alcohol & Not known & Not known & 70 unit per week & Nil \\
\hline Site & Left base of tongue & Left tonsil & Left base of tongue & Right tonsil \\
\hline T category ${ }^{a}$ & T3 $($ T3) & T2 (T2) & $\mathrm{T} 1(\mathrm{~T} 1)$ & $\mathrm{T} 4$ (T4a) \\
\hline N category ${ }^{a}$ & N2 (N2c) & N1 (N2b) & N1 (N2b) & N1 (N2b) \\
\hline M category ${ }^{a}$ & $\mathrm{MO}(\mathrm{MO})$ & MO (M0) & MO (MO) & MO (MO) \\
\hline Stage $^{a}$ & II (IVA) & I (IVA) & I (IVA) & III (IVA) \\
\hline p16 IHC & Positive & Positive & Positive & Positive \\
\hline HR-HPV DNA ISH & Positive & Positive & Negative & Positive \\
\hline Genotype & HPV16 & HPV16 & HPV16 & HPV16 \\
\hline Species & European T350G & European T350G & European & European \\
\hline Treatment & Chemoradiotherapy & $\begin{array}{l}\text { TOLS }{ }^{\mathrm{b}} \text {, left neck } \\
\text { dissection, adjuvant } \\
\text { radiotherapy }\end{array}$ & $\begin{array}{l}\text { Left neck dissection } \\
\text { only. Declined } \\
\text { further treatment }\end{array}$ & Chemoradiotherapy \\
\hline Overall survival & $\begin{array}{l}\text { Alive disease free at } \\
85 \text { months }\end{array}$ & $\begin{array}{l}\text { Alive disease free at } \\
61 \text { months }\end{array}$ & $\begin{array}{l}\text { Alive with loco- } \\
\text { regional disease at } \\
48 \text { months }\end{array}$ & $\begin{array}{l}\text { Dead at } 9 \text { months } \\
\text { Loco-regional } \\
\text { disease }\end{array}$ \\
\hline
\end{tabular}

a UICC TNM8 (UICC TNM7).

b TOLS = trans-oral laser surgery. 
Table 1 (continued) HPV related squamous cell carcinoma in four couples.

\begin{tabular}{|c|c|c|c|c|}
\hline & \multicolumn{2}{|c|}{ Couple 3} & \multicolumn{2}{|c|}{ Couple 4} \\
\hline Sex & Male & Female & Male & Female \\
\hline Age at diagnosis & 64 & 70 & 61 & 55 \\
\hline Year of diagnosis & 2009 & 2015 & 2015 & 2014 \\
\hline $\begin{array}{l}\text { Duration of } \\
\text { relationship }\end{array}$ & \multicolumn{2}{|c|}{50 years } & \multicolumn{2}{|c|}{39 years } \\
\hline $\begin{array}{l}\text { Interval between } \\
\text { couple diagnosis }\end{array}$ & \multicolumn{2}{|c|}{64 months (male index) } & \multicolumn{2}{|c|}{16 months (female index) } \\
\hline Smoking status & Never & Never & Never & Never \\
\hline Alcohol & Nil & Nil & 8 units/week & 4 units/week \\
\hline Site & Left tonsil & Right tonsil & Left tongue base & Right tonsil \\
\hline T category ${ }^{a}$ & T2 (T2) & T2 (T2) & T2 (T2) & T2 (T2) \\
\hline N category ${ }^{a}$ & N1 (N2b) & N1 (N2b) & N1 (N2b) & N1 (N2b) \\
\hline M category ${ }^{a}$ & MO (M0) & MO (M0) & MO (MO) & MO (MO) \\
\hline Stage $^{a}$ & I (IVA) & I (IVA) & I (IVA) & I (IVA) \\
\hline p16 IHC & Positive & Positive & Positive & Positive \\
\hline HR-HPV DNA ISH & Positive & Positive & Positive & Positive \\
\hline Genotype & HPV16 & HPV16 & HPV16 & HPV16 \\
\hline Species & European & European & European & European T350G \\
\hline Treatment & Chemoradiotherapy & Chemoradiotherapy & $\begin{array}{c}\text { Bilateral neck } \\
\text { dissections, } \\
\text { chemoradiotherapy }\end{array}$ & Chemoradiotherapy \\
\hline Overall survival & $\begin{array}{l}\text { Alive disease free } \\
91 \text { months }\end{array}$ & $\begin{array}{l}\text { Alive disease free } \\
32 \text { months }\end{array}$ & $\begin{array}{l}\text { Alive disease free } \\
25 \text { months }\end{array}$ & $\begin{array}{l}\text { Alive disease free } \\
41 \text { months }\end{array}$ \\
\hline
\end{tabular}


Table 2 HPV related squamous cell carcinoma previously reported in five couples [12-15]

\begin{tabular}{|c|c|c|c|c|}
\hline \multirow{3}{*}{ Sex } & \multicolumn{2}{|c|}{ Uemaetomari et al [12] } & \multicolumn{2}{|c|}{ Haddad et al [13] } \\
\hline & \multicolumn{2}{|c|}{ Couple 1} & \multicolumn{2}{|c|}{ Couple 1} \\
\hline & Male & Female & Male & Female \\
\hline Age at diagnosis & 67 & 63 & 75 & 75 \\
\hline Year of diagnosis & 2004 & 2005 & Not stated & Not stated \\
\hline $\begin{array}{l}\text { Duration of } \\
\text { relationship }\end{array}$ & \multicolumn{2}{|c|}{ Not stated } & \multicolumn{2}{|c|}{ Not stated } \\
\hline $\begin{array}{l}\text { Interval between } \\
\text { couple diagnosis }\end{array}$ & \multicolumn{2}{|c|}{12 months (male index tumour) } & \multicolumn{2}{|c|}{0 months (synchronous tumours) } \\
\hline Smoking status & Not stated & Not stated & $\begin{array}{c}\text { Former smoker } \\
\text { (25 years ago) }\end{array}$ & $\begin{array}{c}\text { Former smoker } \\
\text { (10 years ago) }\end{array}$ \\
\hline Alcohol & Not stated & Not stated & $\begin{array}{l}\text { Past heavy user } \\
\text { ( } 25 \text { years ago) }\end{array}$ & Non-drinker \\
\hline Site & Right tonsil & Left tonsil & $\begin{array}{c}\text { Neck } \\
\text { Laterality not stated }\end{array}$ & Right tonsil \\
\hline T category ${ }^{a}$ & $\mathrm{~T} 1(\mathrm{~T} 1)$ & T2 (T2) & TX $(T X)$ & $\mathrm{T} 1(\mathrm{~T} 1)$ \\
\hline N category ${ }^{a}$ & N1 (N2b) & N2 (N2c) & N1 (N2a) & N1 (N1) \\
\hline M category ${ }^{a}$ & $\mathrm{MO}(\mathrm{M0})$ & $\mathrm{M0}(\mathrm{M0})$ & MO (M0) & M0 (M0) \\
\hline Stage ${ }^{a}$ & I (IVA) & II (IVA) & I (IVA) & $\mathrm{I}(\mathrm{III})$ \\
\hline p16 IHC & Not stated & Not stated & Not stated & Positive \\
\hline HR-HPV DNA ISH & Not stated & Not stated & Not stated & Not stated \\
\hline Genotype & HPV16 & HPV16 & HPV16 & HPV16 \\
\hline Species & Not stated & Not stated & European & European \\
\hline Treatment & $\begin{array}{l}\text { Radiotherapy, } \\
\text { surgery for local } \\
\text { recurrence }\end{array}$ & Radiotherapy & Not stated & $\begin{array}{l}\text { Tonsillectomy, neck } \\
\text { dissection }\end{array}$ \\
\hline Overall survival & Not stated & Not stated & Not stated & Not stated \\
\hline
\end{tabular}

a UICC TNM8 (UICC TNM7).

b TORS = trans-oral robotic surgery. 
Table 2 continued

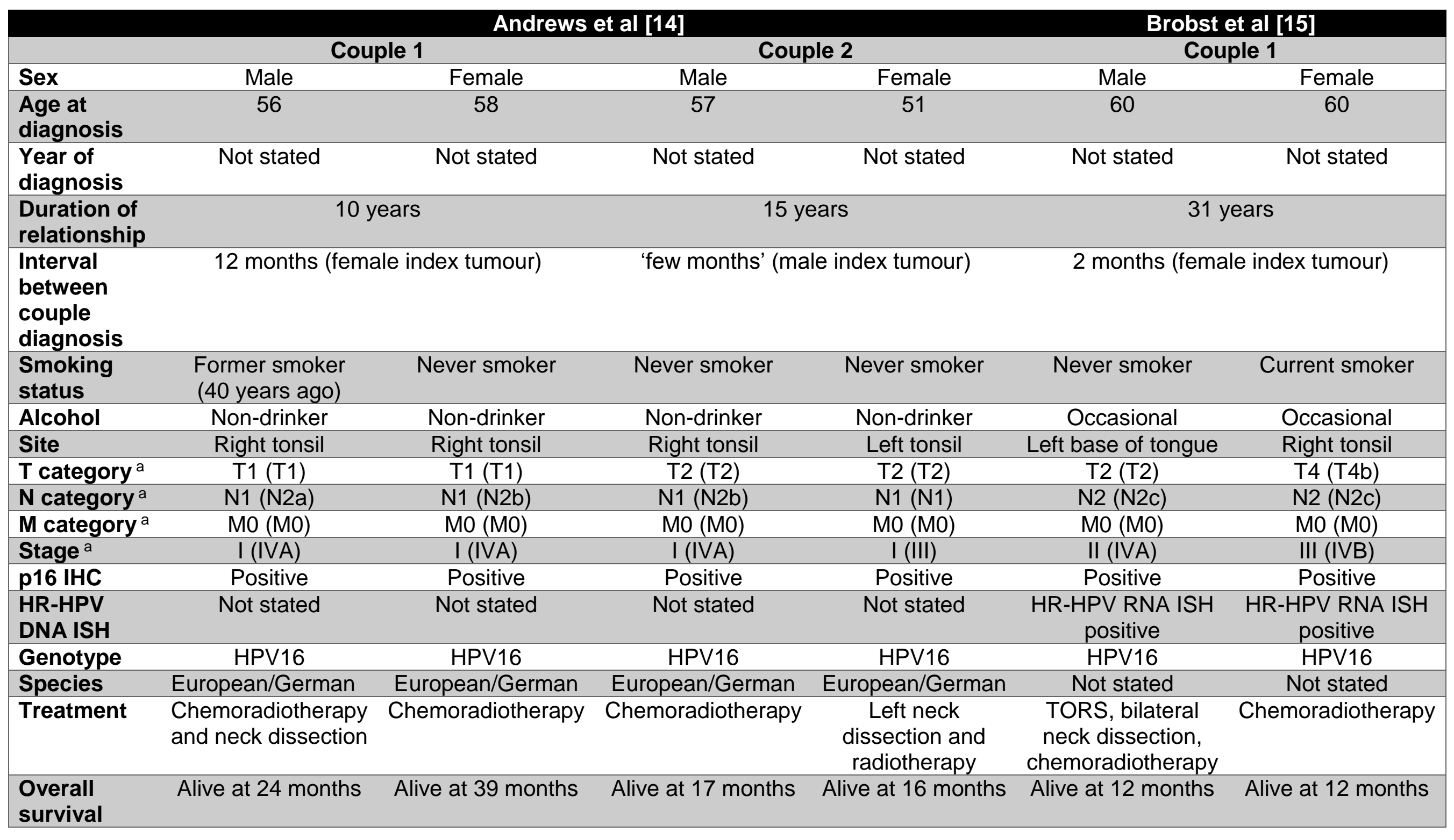

